\title{
KANOLA YAĞINDAN METİL ESTER ÜRETİMİ İÇİN KALSİYUM OKSİT DESTEKLİ HETEROJEN KATALİZÖR TASARIMI
}

\author{
Nezahat BOZ \\ Gazi Üniversitesi, Mühendislik Fakültesi, Kimya Mühendisliği Bölümü, 06570, Maltepe, Ankara \\ nboz@gazi.edu.tr
}

(Geliş/Received: 02.04.2014; Kabul/Accepted: 16.10.2015)

ÖZET

\begin{abstract}
Kanola yağından metil esterlerin üretilmesinde kullanmak için, potasyum karbonat $\left(\mathrm{K}_{2} \mathrm{CO}_{3}\right)$ 'ın farklı yükleme oranlarında (ağırlıkça $\mathrm{K}_{2} \mathrm{CO}_{3} / \mathrm{CaO}$ : \% 1-5 aralığında) sulu çözeltisinde destek materyali (CaO)'ne emdirilmesiyle kalsiyum oksit destekli katalizörler hazırlandı. Sentezlenen katalizörlerin aktivite testleri kanola yağının kesikli bir reaktörde metanol ile yağ asidi metil esteri (YAME) vermek üzere, 298-333 K sıcaklık aralığında, 6/1-15/1 metanol/yă̆ oranlarında, yağ miktarı temeli üzerinden ağırlıç̧a \%1-7 farklı katalizör yüklenerek ve 1-8 saatlik reaksiyon süresi koşullarında transesterifikasyon reaksiyonu ile yapıldı. Yapılan deneyler sonucunda, kalsiyum oksit destekli katalizörler arasında, ağırlıkça $\% 5 \mathrm{~K}_{2} \mathrm{CO}_{3} / \mathrm{CaO}$ katalizörü en yüksek dönüşümü verdi. Bu dönüşüm için koşullar: alkol/yăg: 15/1; katalizör miktarı yağın kütlesi temel alınarak ağırlıkça \%3; reaksiyon süresi: 8 saat; kesikli reaktör; 600 rpm karıştırma hızı; reaksiyon sıcaklığı: $333 \mathrm{~K}$ ve metil ester verimi: \%97. Sadece \%5 $\mathrm{K}_{2} \mathrm{CO}_{3} / \mathrm{CaO}$ katalizörü $773 \mathrm{~K}$ firın sıcaklığında 3 saat süreyle kalsine edildiğinde düşük yüzey alanı ve düşük trigliserit dönüşümü vermiştir. Hem kalsine edilen hem de kalsine edilmeyen $\% 5 \mathrm{~K}_{2} \mathrm{CO}_{3} / \mathrm{CaO}$ katalizörlerinin aktifliğindeki önemli olmayan bir kayıp reaksiyon karışımında çözünmüş katalizör aktif merkezlerinde heterojen katalizli reaksiyon yanında homojen reaksiyonun da yürüdüğ̈̈nü göstermektedir.
\end{abstract}

Anahtar Kelimeler: Kalsiyum oksit destekli katalizörler, transesterleşme, kanola yağı ve biyodizel üretimi

\section{CALCIUM OXIDE BASED HETEROGENEOUS CATALYST DESIGN FOR THE PRODUCTION OF METHYL ESTERS FROM CANOLA OIL}

\begin{abstract}
A calcium oxide $(\mathrm{CaO})$ supported catalysts for use in the production of methyl esters from canola oil were prepared by the impregnation of potassium carbonate $\left(\mathrm{K}_{2} \mathrm{CO}_{3}\right)$ into the support material $(\mathrm{CaO})$ at the different loading ratios of $\mathrm{K}_{2} \mathrm{CO}_{3}\left(\mathrm{~K}_{2} \mathrm{CO}_{3} / \mathrm{CaO}\right.$ ranges by weight: $\left.1-5 \%\right)$ in aqueous solutions. Synthesized catalysts were tested in a liquid batch reactor for the transesterification of canola oil with methanol resulting in fatty acid methyl ester (FAME) at the temperature range of 298-338 K, methanol/oil ratio varying between 6/1-15/1, different catalyst loading (the range of $1-7 \%$ by weight of the amount of fat basis) and 1-8 hours of reaction duration. As a result of the experiments, of calcium oxide supported catalysts, catalyst $5 \%$ by weight $\mathrm{K}_{2} \mathrm{CO}_{3} / \mathrm{CaO}$ (uncalcined) was the highest conversion at the following reaction conditions: alcohol/oil: $15 / 1$, the catalyst based on the weight of the mass of oil in the amount of 3\%, reaction time: 8 hours, batch reactor; 600 rpm stirring speed, methyl ester yield: $97 \%$, reaction temperature: $333 \mathrm{~K}$. Only $5 \% \mathrm{~K}_{2} \mathrm{CO}_{3} / \mathrm{CaO}$ catalyst was calcined at oven temperature of $773 \mathrm{~K}$ for 3 hours. It gave lower surface area and lower triglyceride conversion comparing with uncalcined $5 \% \mathrm{~K}_{2} \mathrm{CO}_{3} / \mathrm{CaO}$ catalyst. Reusability of calcined and uncalcined $5 \% \mathrm{~K}_{2} \mathrm{CO}_{3} / \mathrm{CaO}$ catalyst was also tested for two times in the same reaction condition. A non-significant loss of activity of the catalysts implied that homogeneously and heterogeneously catalyzed transesterification reactions occurred simultaneously during the reaction time.
\end{abstract}

Keywords: Calcium oxide supported catalysts, transesterification, canola oil and biodiesel production 


\section{GÍRISŞ (INTRODUCTION)}

Son yıllarda fosil yakıt rezervlerinin azalması, karbon dioksit ve metan gazlarının sera etkisi ve aşırı çevre kirliliği etkisi alternatif yakıt araştırmalarını yoğunlaştırmıştır. Yenilenebilir enerji kaynaklarından büyük potansiyele sahip biyokütle ve biyodizel önemli alternatif yakıtlar olarak dikkat çekmektedir. Biyodizel biyobozunur olması, anti-toksik ve düşük karbondioksit emisyonuyla iyi bir alternatif ve stratejik bir yakıttır $[1,2]$. Genel olarak orta uzunlukta yağ asidi zincirlerini $\left(\mathrm{C}_{16}-\mathrm{C}_{18}\right.$ karbonlu) içeren bir mono-alkil ester olan ve yağ asidi metil esteri olarak bilinen biyodizel, bitkisel yağların (ayçiçeği, soya, kanola ve mısır yağları) metanol ile $\mathrm{NaOH}$ veya $\mathrm{KOH}$ gibi alkali katalizörle ya da asidik katalizörler varlığında transesterleşme reaksiyonu ile üretilir [4]. Ticari uygulamalarda homojen alkali katalizörlü biyodizel üretimi bir saat gibi çok kısa bir zamanda gerçekleştirilmesine rağmen; reaksiyon ortamından bazik katalizörü uzaklaştırmak, ürünün saflaştırma maliyeti, ortamda su ve serbest ya $\breve{g}$ asitlerinin varlığında yan reaksiyon olarak sabun oluşumu gibi dezavantajlar içerir [5]. Biyodizel üretimi için diğer seçeneklerden biri enzimatik transesterleşmedir. Fakat enzimlerin yüksek fiyatları ve reaksiyon süresinin uzunluğu enzim katalizörlü sistemlerin ticari hale gelmesini kısıtlamaktadır [6, 7]. Biyodizel üretiminde yemeklik yağ atıklarının değerlendirilmesi hem üretimde hammaddenin ucuza mal edilmesi hem de çevre dostu olması bakımında son yıllarda önem kazanmıştır. Transesterleşme reaksiyonunda kullanılacak atık yağların yüksek serbest yağ asidi ve su içeriğine sahip olması bazik katalizör varlığında sabun oluşumuna neden olur [8]. Bunu önlemek amacı ile bazik katalizörler yerine asidik katalizörler tercih edilmektedir. Bu uygulamada genellikle önce yağ asitlerinin esterleşme reaksiyonu bir asidik katalizörle yapılmakta ardından transesterleşme reaksiyonu ile biyodizel elde edilmektedir [3, 8]. Ayrıca distilasyon metodu ile de atık yağın serbest yağ asidi miktarı düşürüldükten sonra transesterleşme reaksiyonunda yüksek verim elde edildiği bildirilmiştir $[9,10]$. Günümüzde homojen alkali katalizör varlığında biyodizel üretiminde reaksiyon ortamından katalizörün uzaklaştırılması, biyodizelin safsızlığı, su ve serbest yağ asitlerinin varlı̆̆ında sabun oluşumu gibi dezavantajlar nedeni ile araştırmacılar daha yüksek aktivite ve seçicilik gösteren heterojen katalizör içeren reaksiyon sistemleri üzerine yoğunlaşmış̧ır [11-16]. Son y1llarda kalsiyum oksit $(\mathrm{CaO})[17,19]$ ve kalsiyum oksit destekli katalizörler yüksek özellikle baziklik göstermesi ( $\mathrm{pKa}$ değeri $=\mathrm{H}_{-}=26,5$; kimyada baziklik kuvveti asidik indikatörlerin $\mathrm{pKa}$ değeri ile ifade edilir, baziklik kuvveti aynı zamanda $\mathrm{H}_{\text {_ gösterimi ile }}$ de ifade edilir), ucuzluğu ve transesterleşme reaksiyonlarında aktif olmalarından dolayı ele alınmıştır [20-23]. Karanja yağının transesterleşme reaksiyonunda bazik $\mathrm{Li} / \mathrm{CaO}, \mathrm{Na} / \mathrm{CaO}$ ve $\mathrm{K} / \mathrm{CaO}$ katalizörleri kullanılarak ağırlıkça \%98,6 metil ester içeren biyodizel elde edilmiștir [24]. Son yıllarda üretilen biyodizel miktarındaki artış ve biyodizelin ticarileşmesindeki yaygınlık üretilen biyodizelin yakıt özelliklerine ve kalitesine çok bağlıdır. Biyodizel günümüzde Amerika (ASTM D 6751) ve Avrupa Birliği (EN 14214) standartlarına göre karakterize edilmektedir. Yapılan farklı çalışmalarda çeşitli bitkisel yağlardan üretilen biyodizellerin yakıt özelliklerinin standartlara uygun nitelikte olduğu ve dizel motorlarda kullanılabileceği gösterilmiştir [2527].

$\mathrm{Bu}$ çalı̧̧mada kanola yağından metanolle metil ester üretiminde transesterleşme reaksiyonunda metil ester üretim verimini artırmak için kalsiyum oksit destek malzemesine farklı oranlarda potasyum karbonat emdirilmek suretiyle kalsiyum oksit destekli bir heterojen katalizör tasarımı üzerinde çalışıldı. Transesterleşme reaksiyonu sıvı kesikli reaktörde yapılarak, alkol/yağ oranı, reaksiyon sıcaklığı, katalizör miktarı, reaksiyon süresi, katalizörün geri dönüşümü ve tekrar kullanılabilirliği araştırıldı. Sentezlenen katalizörlerin karakterizasyonu BrunauerEmmett-Teller (BET) yüzey alanı, X-şsını difraktometresi (XRD), taramalı elektron mikroskobu (SEM) ve $\mathrm{N}_{2}$ adsorpsiyon-desorpsiyon yöntemleriyle, bazik kuvvetleri ve baziklikleri Hammett indikatörleri yöntemi ile belirlendi.

\section{DENEYSEL YÖNTEMLER (EXPERIMENTAL METHODS)}

\subsection{Materyaller (Materials)}

$\mathrm{Bu}$ çalışmada kimyasal madde olarak analitik saflıkta \%99,8 metanol (Carlo Erba Reagents, 67-56-1), potasyum karbonat (Merck, 104928) ve kalsiyum oksit (Sigma-Aldrich, 248568) kullanıldı. Marketten temin edilen ticari kanola yağı (Kristal) reaktant olarak kullanıldı. Metil heptadekanoat (Merck, 109754) metil ester analizinde iç standart olarak kullanıldı. Kanola yağının serbest yağ asidi içeriği AOCS Cd 3a-63 Resmi metoduna göre (\%) 0,085 olarak ölçüldü [28].

\subsection{Katalizör Hazırlanması ve Karakterizasyonu} (Catalyst Preparation and Characterization)

Bu çalışmada kullanılan heterojen bazik katalizörler farklı derişimde hazırlanan potasyum karbonat çözeltisinin kalsiyum oksit destek malzemesi içine emdirilmesiyle hazırlandı. Katalizör sentezinde temel değişken olarak destek maddesine yüklenen potasyum karbonat miktarı (ağırlıkça \%1-5 aralığı)'nın etkisi izlendi. Kalsinasyon sıcaklığ $773 \mathrm{~K}$ ve kalsinasyon süresi 3 saat olarak sadece $\% 5 \quad \mathrm{~K}_{2} \mathrm{CO}_{3} / \mathrm{CaO}$ katalizörüne uygulandı. Destek malzemesi $\mathrm{CaO}$ 'in tüm gözeneklerinin kullanılması sağlanması için 
emdirme işleminde vakum uygulandı. Hazırlanan katalizör firında (Firma Katalog no) $373 \mathrm{~K}$ sicaklıkta 24 saat boyunca kurutularak reaksiyonda kullanıma hazır hale getirildi. Kalsinasyonun etkisini araştırmak amaciyla sadece $\% 5 \mathrm{~K}_{2} \mathrm{CO}_{3} / \mathrm{CaO}$ katalizörü kalsine edilerek transesterleşme reaksiyonunda test edildi. Katı bazik katalizörlerin bazik kuvvetleri ve baziklikleri Xie ark.'ın [29] çalışmasında verilen Hammett indikatörü metodu ile belirlendi. Katalizör parçacıklarının BET yüzey alanını belirlemek için çok noktalı BET sorptometre kullanılarak azot soğurma yöntemi ile karakterize edildi. Her bir yüzey alan ölçümü öncesi numuneler bir gece boyunca firın içinde vakum altında $383 \mathrm{~K}$ 'de tutuldu. Saf $\mathrm{CaO}$ ve ağırlıkça \%5 potasyum karbonat yüklenen kalsiyum oksit $\% 5 \quad \mathrm{~K}_{2} \mathrm{CO}_{3} / \mathrm{CaO}$ katalizörünün kalsinasyon öncesi ve sonrasında SEM fotografları Jeol-JSM-6400 Scanning Microscope kullanılarak çekildi. Saf $\mathrm{CaO}$, saf $\mathrm{K}_{2} \mathrm{CO}_{3}$ ve sentezlenen katalizörlerden en yüksek dönüşümü veren $\% 5 \quad \mathrm{~K}_{2} \mathrm{CO}_{3} / \mathrm{CaO}$ katalizörü kalsinasyon öncesi ve sonrası Rigaku/D/MAX 2200 difraktometre kullanılarak X-1şınları spektroskopisi ile analiz edildi. Oda sıcaklığında $40 \mathrm{kV} / 40 \mathrm{~mA}$ 'da çalışan bir $\mathrm{Cu}$ X-1şını tüpünde elde edilen $\mathrm{CuK}_{\alpha}$ radyasyonu kullanılarak Bragg açısı 5-75 arasında tutulmuştur.

\subsection{Transesterleşme Reaksiyonu (Transesterification Reaction)}

Biyodizel, yani yağ asidi metil esterleri trigliseritlerin transesterleşmesinin gerçekleştiği denklem aşağıda verildi.

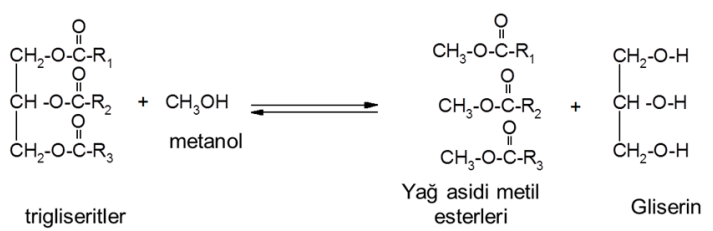

Transesterleşme reaksiyonu bir geri akış soğutucusu, numune alma bölümü, sıcaklık ölçme bölümü ve bir manyetik karıştırıcı ile donatılmış 250 mL'lik kesikli cam reaktör içinde gerçekleştirildi. Prosesteki kütle transfer limitasyonlarının dönüşüme etkisini önlemek için tüm deneylerde karıştırma hızı 600 rpm'de sabit tutuldu. Transesterifikasyon reaksiyonunda önemli parametrelerden besleme oranı (alkol/yağ: 6/1-15/1), reaksiyon sicaklığı (298-333 K), reaksiyon süresi (1-8 saat) ve katalizör/yağ ağırlık oranı (\%1-7) farklı miktarda potasyum karbonat içeriğine sahip kalsiyum oksit destekli katalizörlerin varlığında araştırıldı. Deneyler atmosfer basıncı altında yapıldı. Deneylerde kimyasal analiz için numuneler 1 saatlik aralıklarla reaktör çıkışından alınarak yaklaşık 2-3 $\mathrm{ml}$ hacımlarda toplandı. Reaksiyon süresi, reaktantlar ve katı katalizör reaktöre ilave edilir edilmez başlatıldı ve 8 saatlik bir sürede tamamlandı. Reaksiyonun tamamlanmasından sonra tüm reaksiyon karışımı ayırma hunisine aktarılarak metil ester ve gliserinin yoğunluk farkından dolayı gece boyunca bekletilerek ayrılması sağlandı. Elde edilen metil ester fazı (üst faz) metil ester verimini hesaplayabilmek için alev iyonizasyon dedektörü (FID) ve kapiler bir kolon ile (CARBOWAX 20M) donatılmış bir gaz kromotografi (GC) cihazı (Agilent 6890) kullanılarak TS EN 14103 standardına [30] göre analiz edildi.

Kromatogramlardaki piklerden tüm veri noktaları üç noktanın ortalaması alınarak \%95 güven aralığında Student-t dağılımına göre belirlendi ve rapor edildi. Ayrıca Tablo 1 ve 2 de verilen trigliserit dönüşümü $\left(X_{T G}\right)$, elde edilen metil ester fazındaki toplam trigliserit $\left(T G_{y a g ̆}\right)$ ve yă içindeki toplam trigliserit $\left(T G_{\text {ester }}\right)$ miktarları ölçülerek Eşitlik 1'e göre hesaplandi [31].

$$
X_{T G}=\frac{T G(y a \breve{g})-T G(\text { ester })}{T G(y a \breve{g})}
$$

\section{BULGULAR VE TARTIŞMA (RESULTS AND DISCUSSION)}

\subsection{Katalizör Characterization) \\ Karakterizastonu \\ (Catalyst}

Sentezlenen $\mathrm{CaO}$ destekli katı bazik katalizörlerin transesterleşme reaksiyonları kanola yağı ve kısa zincirli bir alkol olan metanol ile yapıldı. Katalizörlerin baziklikleri (mmol/g) ve bazik kuvvetleri (pKa değeri $=H_{-}$) ile reaksiyonda vermiş oldukları trigliserit ve metil ester verimleri Tablo 1'de özetlenmiştir.

Tablo 1. Sentezlenen katalizörlerin baziklik, yüzey alanı ve katalitik performansları (Basicity, surface area and catalytic performances of synthesized catalysts)

\begin{tabular}{|l|c|c|c|c|}
\hline & $\begin{array}{l}\text { Baziklik } \\
(\mathrm{mmol} / \mathrm{g})\end{array}$ & $\begin{array}{l}\mathrm{BET} \\
\left(\mathrm{m}^{2} / \mathrm{g}\right)\end{array}$ & $\begin{array}{l}\text { Trigliserit } \\
\text { Dönüşümü } \\
\mathrm{X}_{\mathrm{TG}}(\%)\end{array}$ & $\begin{array}{l}\text { Metil } \\
\text { Ester } \\
\text { Verimi } \\
(\%)\end{array}$ \\
\hline $\mathrm{CaO}$ & - & 10,52 & - & - \\
\hline $\begin{array}{l}\% 1 \\
\mathrm{~K}_{2} \mathrm{CO}_{3} / \mathrm{CaO}\end{array}$ & 0,54 & - & 61,56 & 65 \\
\hline $\begin{array}{l}\% 1,5 \\
\mathrm{~K}_{2} \mathrm{CO}_{3} / \mathrm{CaO}\end{array}$ & 0,56 & - & 62,94 & 67 \\
\hline $\begin{array}{l}\% 3 \\
\mathrm{~K}_{2} \mathrm{CO}_{3} / \mathrm{CaO}\end{array}$ & 0,58 & - & 63,80 & 69 \\
\hline $\begin{array}{l}\% 5 \\
\mathrm{~K}_{2} \mathrm{CO}_{3} / \mathrm{CaO}\end{array}$ & 0,69 & 16,27 & 96,50 & 97 \\
\hline $\begin{array}{l}\% 5 \\
\mathrm{~K}_{2} \mathrm{CO}_{3} / \mathrm{CaO} \\
(\mathrm{Kalsine} \\
\text { edilen)* }\end{array}$ & 1,02 & 3,77 & 94,00 & 95 \\
\hline
\end{tabular}

Reaksiyon koșulları: metanol/ya $\breve{g}=15 / 1$, sıcaklık=333K, reaksiyon süresi: 8 saat, katalizör miktarı = ağırlıkça \%3. Tüm malzemelerde Bazik Kuvvet Aralığı (pKa değeri $\left.=\mathrm{H}_{2}\right)=15<\mathrm{H}_{-}<18,4$.

*Kalsinasyon sıcaklığı ve zamanı, $7 \overline{73} \mathrm{~K}$ ve 3 saat.

Sentezlenen bazik katalizörlerin kanola yağı ve metanol ile birlikte yapılan transesterleşme reaksiyonlarında bütün aktivite ölçümleri aynı reaksiyon koşulları (reaksiyon sıcaklığı: $333 \mathrm{~K}$, alkol/yağ: 15/1, katalizör yüklemesi: ağırlıç̧a \%3, 
reaksiyon süresi: 8 saat) altında yapıldı. Tablo 1'deki katalizörlerden sadece $\% 5 \quad \mathrm{~K}_{2} \mathrm{CO}_{3} / \mathrm{CaO} \quad$ (kalsine edilen) katalizörü $773 \mathrm{~K}$ sicaklıkta 3 saat boyunca kalsine edildi, diğerleri kalsinasyona tabi tutulmamıştır. $\mathrm{CaO}$ destek malzemesi 10,52 $\mathrm{m}^{2} / \mathrm{g}$ yüzey alanı vermesine rağmen $\% \quad 5$ potasyum karbonat yüklemesi yapılmış ve kalsinasyona tabi tutulmamış \%5 $\quad \mathrm{K}_{2} \mathrm{CO}_{3} / \mathrm{CaO}$ katalizörü $16,27 \quad \mathrm{~m}^{2} / \mathrm{g}$ düzeyinde yüksek yüzey alanı vermiştir. Kalsine edilen katalizör ise daha düşük $3,77 \mathrm{~m}^{2} / \mathrm{g}$ yüzey alanı göstermiştir. Kalsine edilen katalizör, kalsinasyon esnasında 1sıl etkiyle yapısında değişmeler olduğundan, daha düşük BET yüzey alanı vermiştir. Emdirme işlemi sırasında sulu potasyum karbonat kalsiyum oksit destek malzemesinin gözeneklerine dolarak kalsiyum hidroksite, $\mathrm{Ca}(\mathrm{OH})_{2}$, dönüşerek destek malzemesinin yüzey alanında artışa neden olmuştur. Yapılan bir çalışmada $\mathrm{Ca}(\mathrm{OH})_{2}$ 'in yüzey alanı $16 \mathrm{~m}^{2} / \mathrm{g}$ olarak verilmektedir [19] ve bu çalışma bizim bulgularımızı desteklemektedir. Ayrıca kalsinasyon öncesi sentezlenen katalizörün yapısında çoğunlukla kalsiyum hidroksit olduğunu aşağıda verilen XRD sonuçları da desteklemektedir. Katalizörlerden kalsine edilmeyen $\% 5 \quad \mathrm{~K}_{2} \mathrm{CO}_{3} / \mathrm{CaO}$ katalizörü en yüksek metil ester verimi (\%97) ve trigliserit dönüşümünü $(\% 96,5)$ vermiştir (Tablo 1).

Şekil 1'de $\mathrm{CaO}$ destek malzemesinin ve hazırlanan $\% 5 \mathrm{~K}_{2} \mathrm{CO}_{3} / \mathrm{CaO}$ katalizörünün reaksiyon öncesi ve sonrası gözenek boyutu dağılımı verilmiştir. Sentezlenen katalizörün dar gözenek boyutu dağılımına sahip olduğu görülmektedir. Azot adsorpsiyon izotermleri hem $\mathrm{CaO}$ hem de \%5 potasyum karbonat yüklenmiş $\mathrm{CaO}$ katalizörlerinin reaksiyon öncesi ve sonrası için Şekil 2'de verilmiştir. Gözeneklerin çoğu 10-100 nm aralığında bulunmuştur. Reaksiyon sonrası katalizör gözenek çapının genişlediği gözlenmiştir. $\mathrm{Bu}$ durum gözeneklere emdirilmiş $\mathrm{K}_{2} \mathrm{CO}_{3}$ 'ın bir kısmının reaksiyonda çözünerek reaksiyonu sıv1 fazda katalizlediğini göstermektedir.

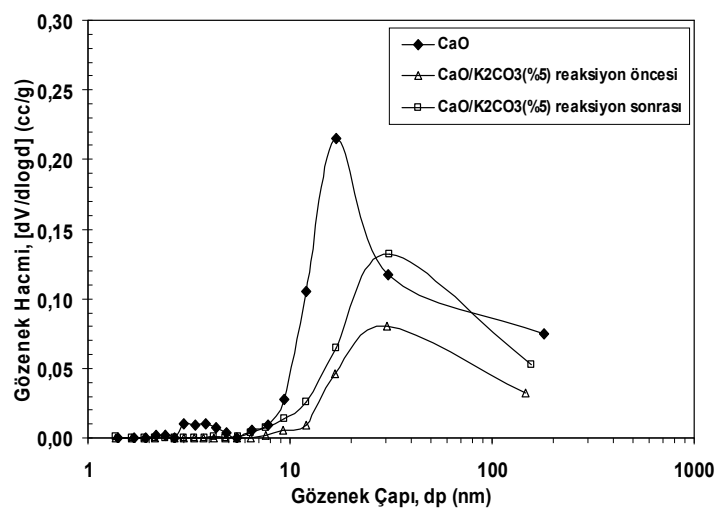

Şekil 1. $\mathrm{CaO}$ ve hazırlanan $\% 5 \quad \mathrm{~K}_{2} \mathrm{CO}_{3} / \mathrm{CaO}$ katalizörünün reaksiyon öncesi ve sonrası gözenek boyutu dağılımı (Pore size distribution of $\mathrm{CaO}$ and $5 \%$ $\mathrm{K}_{2} \mathrm{CO}_{3} / \mathrm{CaO}$ catalyst before and after transesterification)

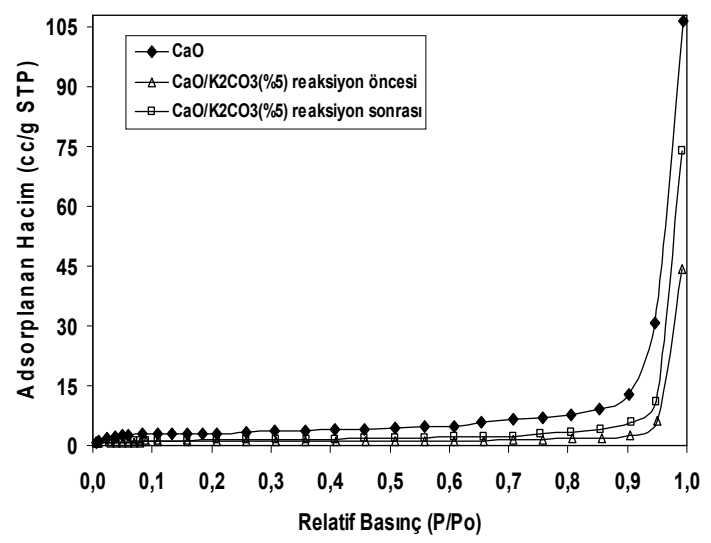

Şekil 2. $\mathrm{CaO}$ ve $\% 5 \quad \mathrm{~K}_{2} \mathrm{CO}_{3} / \mathrm{CaO}$ katalizörünün reaksiyon öncesi ve sonrası azot adsorpsiyon izotermleri (Nitrogen adsorption isotherms of $\mathrm{CaO}$ and $5 \%$ $\mathrm{K}_{2} \mathrm{CO}_{3} / \mathrm{CaO}$ catalyst before and after transesterification)

Kalsinasyon işleminin katalizör yapısına etkisini araştırmak için $\mathrm{CaO}$ destek malzemesi ve $\% 5$ $\mathrm{K}_{2} \mathrm{CO}_{3} / \mathrm{CaO}$ katalizörünün hem 773 K'deki kalsinasyon öncesi hem de kalsinasyon sonrası SEM fotoğrafları Şekil 3'te verilmiştir. Katalizör yapısındaki destek malzemesi $\mathrm{CaO}$ yükleme öncesi kübik yapıda ve parçacık çapı yaklaşık 5-15 $\mu \mathrm{m}$ aralığındadır (Şekil 3a ve 3b). Fakat kalsinasyon öncesi (Şekil 3c) ve sonrası (Şekil 3d) katalizör yüzeyi emdirilen $\mathrm{K}_{2} \mathrm{CO}_{3}$ 'ın etkisiyle daha granül bir form alarak parçacık boyutu yaklaşık 2-5 $\mu \mathrm{m}$ aralığında görülmüştür. Kalsinasyon sonrası (Şekil 3d) katalizör yapısında taneciklerin birbirine yapışık bir hal alarak daha pürüzsüz bir yüzey yapısı elde edilmiştir.

Sentezlenen katalizörlerin, yapıya yüklenen maddenin ve destek malzemesinin XRD çekimleri yapılarak elde edilen malzemenin yapısı araştırılmıştır. Şekil 4'de $\mathrm{CaO}, \mathrm{K}_{2} \mathrm{CO}_{3}, \% 5 \quad \mathrm{~K}_{2} \mathrm{CO}_{3} / \mathrm{CaO}$ kalsinasyon öncesi ve $\% 5 \mathrm{~K}_{2} \mathrm{CO}_{3} / \mathrm{CaO}$ kalsinasyon sonrası XRD pikleri verilmiştir. $\mathrm{CaO}$ tipik olarak beklenen (JCPDS data 77-2376) piklerini $2 \theta=32.36,37.74,53.66$, $64.48,67.7^{\circ}$ 'de vermiştir. $\mathrm{K}_{2} \mathrm{CO}_{3}$ 'e ait piklerde $2 \theta=$ $26.8, \quad 30.62, \quad 32, \quad 35, \quad 38, \quad 40, \quad 54.36, \quad 66.7^{\circ}$ de gözlenmiştir. Ağırlıkça \%5 $\mathrm{K}_{2} \mathrm{CO}_{3}$ yüklenen $\mathrm{CaO}$ katalizörü kalsinasyon öncesi ve sonrası çekilen XRD çekimlerinde (Şekil 4) $\mathrm{Ca}(\mathrm{OH})_{2}$, JCPDS file 84-1264 ve Calcite- $\mathrm{CaCO}_{3}, \mathrm{JCPDS}$ file 86-174 piklerini vermiştir. Calcite- $\mathrm{CaCO}_{3}$ piklerinin kalsinasyon sonrası şiddetleri daha belirgin hale gelmiştir. Kalsinasyon sonrası yapıda gözlenen $\mathrm{Ca}(\mathrm{OH})_{2}$ piklerinin ise şiddetleri azalarak pikler daha yayvan bir hal almıştır. Calcite- $\mathrm{CaCO}_{3}$ pikleri katalizör yüzeyinde koruyucu bir tabaka oluşturarak $\mathrm{Ca}(\mathrm{OH})_{2}$ fazının tekrar karbonlaşmasını önlediği sonucuna varılmıştır. Böylece XRD analizlerine göre kalsinasyon ile yapının kararlılığı sağlanarak reaksiyon ortamında çözünmeyen Kalcit- $\mathrm{CaCO}_{3}$ yapısı elde edilmiştir. 

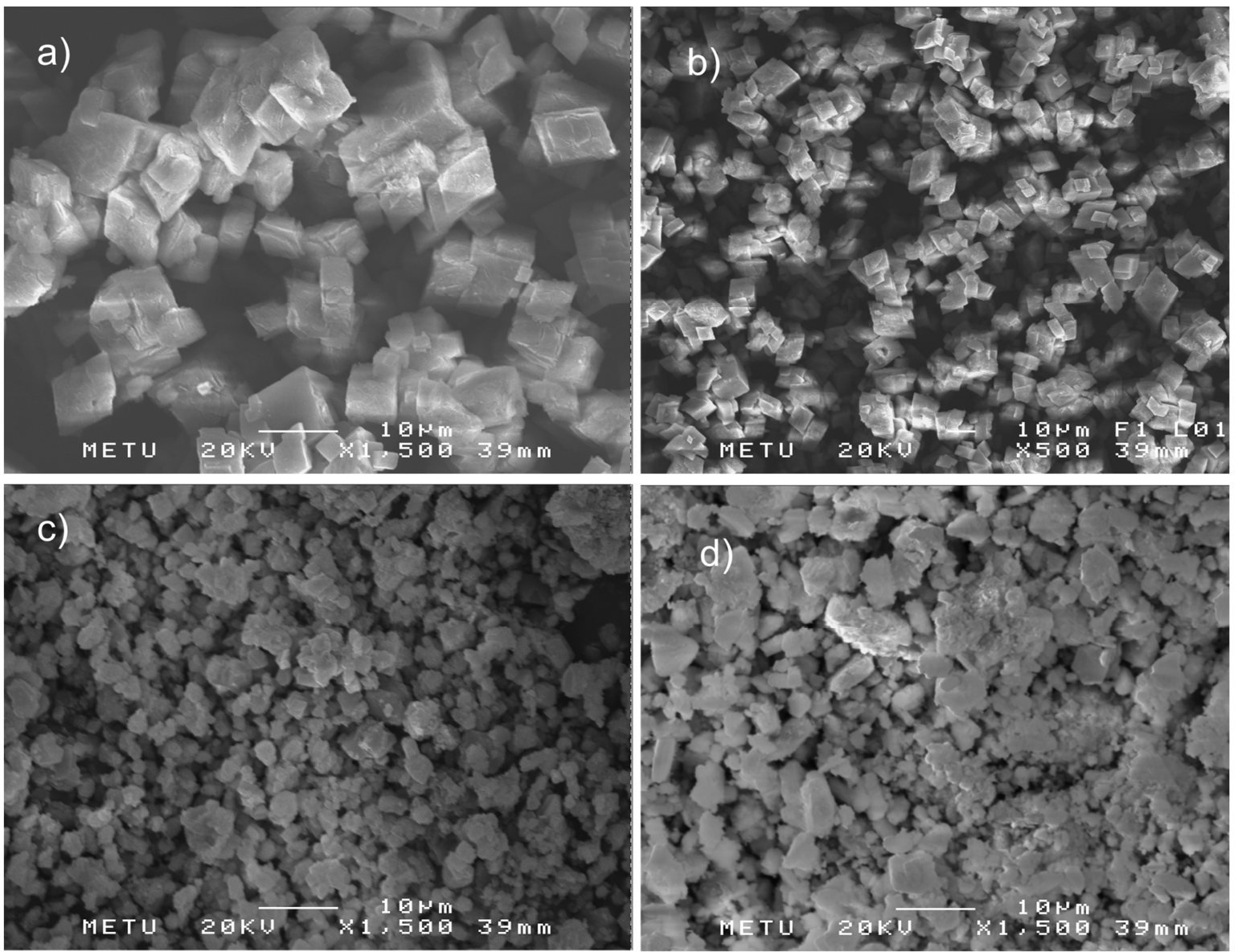

Şekil 3. $\mathrm{CaO}$ ve $\% 5 \mathrm{~K}_{2} \mathrm{CO}_{3} / \mathrm{CaO}$ katalizörünün $\mathrm{SEM}$ fotoğrafları (a) $\mathrm{CaO}$, (b) $\mathrm{CaO}$, (c) $\% 5 \mathrm{~K}_{2} \mathrm{CO}_{3} / \mathrm{CaO}$ kalsinasyon öncesi, (d) $\% 5 \mathrm{~K}_{2} \mathrm{CO}_{3} / \mathrm{CaO}$ kalsinasyon sonras1 (SEM micrographs of $\mathrm{CaO}$ and $5 \% \mathrm{~K}_{2} \mathrm{CO}_{3} / \mathrm{CaO}$ catalyst, (a) $\mathrm{CaO}$, (b) $\mathrm{CaO}$, (c) $5 \% \mathrm{~K}_{2} \mathrm{CO}_{3} / \mathrm{CaO}$ before calcination, (d) $5 \% \mathrm{~K}_{2} \mathrm{CO}_{3} / \mathrm{CaO}$ after calcination)

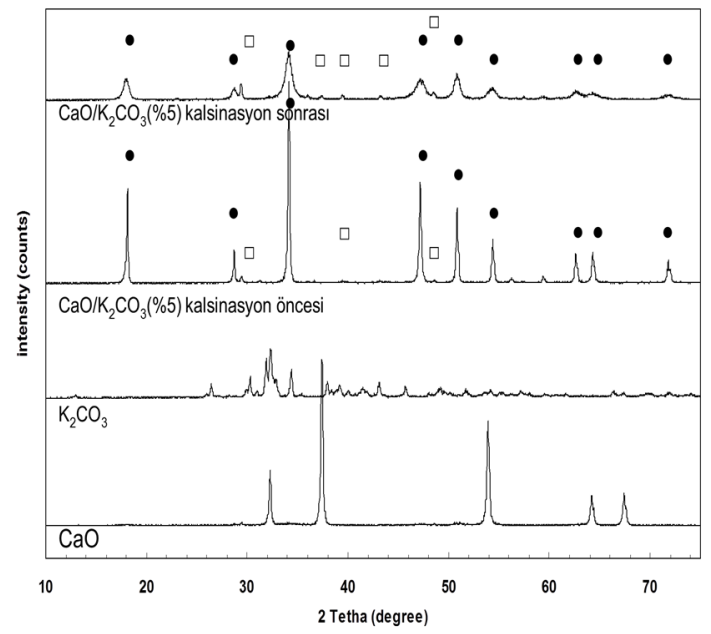

Şekil 4. $\mathrm{CaO}$ ve $\% 5 \mathrm{~K}_{2} \mathrm{CO}_{3} / \mathrm{CaO}$ katalizörünün $\mathrm{XRD}$ eğrileri, (a) $\mathrm{CaO}, \mathrm{K}_{2} \mathrm{CO}_{3}, \% 5 \mathrm{~K}_{2} \mathrm{CO}_{3} / \mathrm{CaO}$ kalsinasyon öncesi, (b) $\% 5 \mathrm{~K}_{2} \mathrm{CO}_{3} / \mathrm{CaO}$ kalsinasyon sonrası (XRD patterns of $\mathrm{CaO}$ and $5 \% \mathrm{~K}_{2} \mathrm{CO}_{3} / \mathrm{CaO}$ catalysts, (a) $5 \% \mathrm{~K}_{2} \mathrm{CO}_{3} / \mathrm{CaO}$ before calcination, (b) $5 \% \mathrm{~K}_{2} \mathrm{CO}_{3} / \mathrm{CaO}$ after calcination), $(\bullet)$ $\left(\mathrm{Ca}(\mathrm{OH})_{2}\right.$, JCPDS file 84-1264), () Calcite- $\mathrm{CaCO}_{3}$, JCPDS file 86-174).

\subsection{Transesterleşme Reaksiyon Parametrelerinin Verime Etkileri (Effects of Transesterification Reaction Variables on Methyl Ester Yield)}

Transesterleşme reaksiyonunda metil ester verimine etki eden en önemli parametreler methanol yağ mol oranı, reaksiyon süresi, reaksiyon sicaklığı ve katalizör miktarıdır. Kanola yağı ile metanolün $60^{\circ} \mathrm{C}$ 'de farklı metanol/yag oranlarının transesterleşme reaksiyonuna etkisi araştırılarak ve sonuçlar Şekil 5'te verilmiştir. Transesterleşme reaksiyonu, ağırlıkça \%3; \%5 $\mathrm{K}_{2} \mathrm{CO}_{3} / \mathrm{CaO}$ katalizör miktarı ile kalsine edilmiş ve kalsine edilmemiş katalizör varlığında 8 saat sürede gerçekleştirilmiştir. $\mathrm{Bu}$ şartlar altında alkol/yağ oranı 15:1'de en yüksek metil ester verimi $\% 97$ olarak kalsine edilmeyen katalizör üzerinde bulunmuştur. Kalsine edilen katalizörlü transesterleşme reaksiyonunda ise $\% 96,5$ metil ester verimi elde edilmiştir. Kalsinasyon öncesi katalizör yapısında $\mathrm{Ca}(\mathrm{OH})_{2}$ yapısı oldukça güçlü XRD pikleri vermiştir. Kalsine edilmeyen katalizör bu nedenle daha yüksek verim göstermiștir. Heterojen katalizli transesterleşme reaksiyonlarında reaksiyon 
hızını artırmak için çoğu kez skokiometrik molar alkol/yăg oranı 3'ten daha yüksek değerlerde çalışılmaktadır. $\mathrm{Bu}$ çalışmada bulunan alkol/yă oran1, bu tip heterojen katalizli reaksiyonlarda literatürdeki [29, 32-34] alkol/yağ oranı aralığında $(5 / 1-275 / 1)$ bulundu.

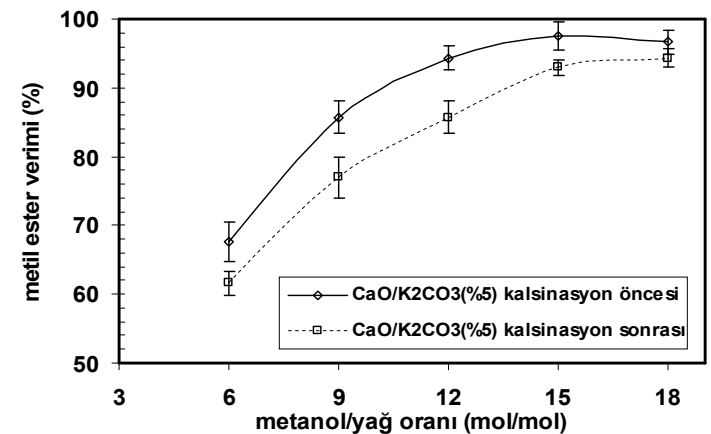

Şekil 5. Metanol/kanola yağ oranının kanola yağının dönüşümüne etkisi (reaksiyon süresi: 8 saat; katalizör miktarı: ağırlıkça \%3; sıcaklık: $333 \mathrm{~K}$ ) (The effects of methanol/canola oil ratio on the canola oil conversion; reaction time: $8 \mathrm{~h}$; catalyst amount: 3 wt. $\%$; temperature: $333 \mathrm{~K}$ )

Reaksiyon sıcaklığı hem reaksiyon hızını hem de metil ester verimini etkilemektedir. $\mathrm{Bu}$ konu bu çalışmada kalsine edilmeyen $\% 5 \quad \mathrm{~K}_{2} \mathrm{CO}_{3} / \mathrm{CaO}$ katalizörü varlığında farklı sıcaklıklarda $(298,318$ ve $333 \mathrm{~K}$ ) diğer reaksiyon koşullarının (reaksiyon süresi: 8 saat; katalizör miktarı: ağırlıkça \%3; methanol/yağ oranı:15/1) aynı olduğu durumda test edilmiştir. Şekil 6'da görüldüğü gibi en yüksek verim metanolün kaynama noktası $\left(65^{\circ} \mathrm{C}\right)$ 'na yakın bir sicaklıkta 333 $\mathrm{K}$ 'de elde edilmiştir. Bu sıcaklıkta reaksiyonun 8 saat sonunda hemen hemen tamamlandığı gözlendi.

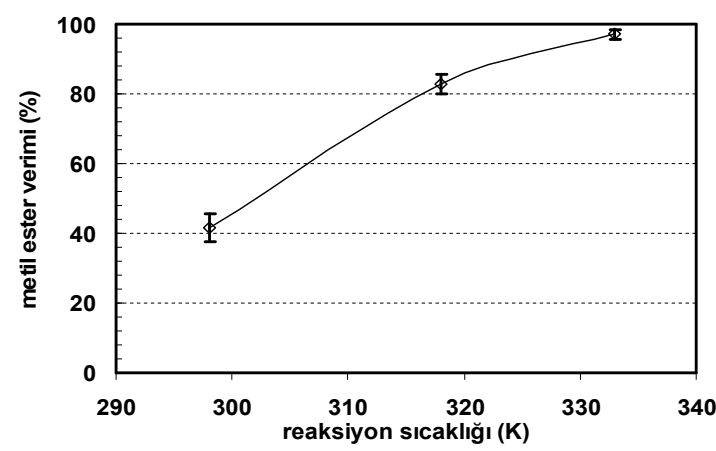

Şekil 6. Sıcaklığın kanola yağının dönüşümüne etkisi (reaksiyon süresi: 8 saat; katalizör miktarı: ağırlıç̧a $\% 3 ;$ metanol/yağ oran1:15/1) (The effects of temperature on the canola oil conversion; reaction time: $8 \mathrm{~h}$; catalyst amount: 3 wt. $\%$; methanol/oil=15/1)

Katalizör miktarının metil ester verimine etkisi kalsine edilmeyen $\% 5 \quad \mathrm{~K}_{2} \mathrm{CO}_{3} / \mathrm{CaO}$ katalizörü varlığında diğer reaksiyon koşullarının (reaksiyon süresi: 8 saat; methanol/yağ oranı:15/1; sıcaklık: 333 K) aynı olduğu şartlarda araştırılarak elde edilen sonuçlar Şekil 7'de verilmiştir. Metil ester verimi katalizör miktarı ile birlikte artmakta ve \%3'ten sonra
\%97 düzeyinde maksimum asimptotta sabit kalmaktadır. Yağ miktarına göre $\% 3$ katalizör miktarı bu reaksiyon şartlarında en uygun miktar olarak bulunmuştur. Katalizör miktarı reaksiyon hızını artırmakla birlikte katı katalizörün reaksiyon sisteminde fazla olması karıştırma sorunlarına neden olmaktadır.

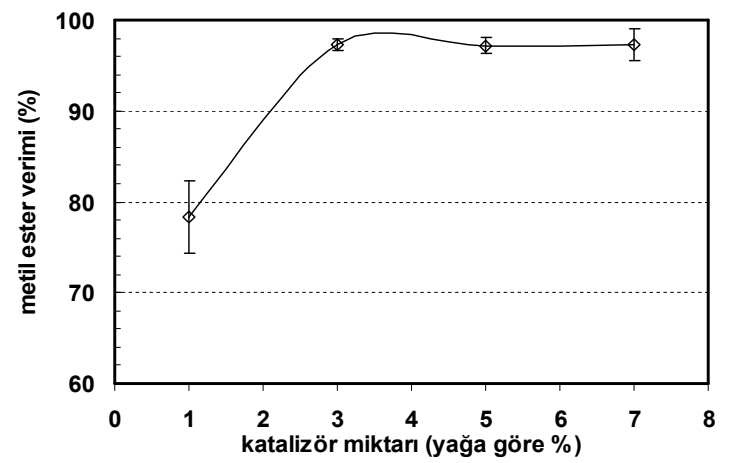

Şekil 7. Katalizör miktarının kanola yağının dönüşümüne etkisi (reaksiyon süresi: 8 saat; sicaklık: $333 \mathrm{~K}$; metanol/yağ oranı:15/1) (The effects of catalyst amount on the canola oil conversion; reaction time: $8 \mathrm{~h}$; temperature: $333 \mathrm{~K}$; methanol/oil=15/1)

\subsection{Katalizörün Geri Dönüșümü ve Tekrar Kullanılabilirliği (Recycle and reusability of the catalyst)}

Katı katalizörlerin reaksiyon süresince kararlılığı ve aktif merkezlerini kaybetmemesi kesikli reaktör sistemlerinde, özellikle reaksiyon süresinin uzun olduğu reaksiyonlarda en önemli parametrelerden biridir [32-34]. Kalsine edilmiş ve kalsine edilmemiş $\% 5 \quad \mathrm{~K}_{2} \mathrm{CO}_{3}$ yüklenen $\mathrm{CaO}$ katalizörlerinin tekrar kullanılabilirliği kanola yağının metanol ile transesterleşme reaksiyonunda aynı reaksiyon şartlarında test edildi. Reaksiyon tamamlandığında katalizör vakum altında süzülerek reaksiyon karışımından ayrılıp metanolle yıkandı. Sonrasında ikinci kullanım için $100^{\circ} \mathrm{C}$ 'de 3 saat kurutularak reaksiyona hazır hale getirildi. Tablo 2'de görüldüğü gibi kalsine edilen katalizör ile edilmeyen katalizörün 2. kullanım sonunda trigliserit dönüşümleri her iki katalizörde yakın değerler elde edilmiş yani hemen hemen sabit kalmıştır. Her iki katalizörde de \%1'den az trigliserit dönüşüm düşüşü gözlenmiştir. Bu durum bazı aktif merkezlerin reaksiyon sırasında katalizör yüzeyinden reaksiyon karışımı içerisine çözünmesi ve reaksiyonu homojen olarak katalizlediği şeklinde açıklanabilir. Her iki katalizörde de 2. kullanım sonunda bazik kuvvet aralığı gerilemiş ve beklendiği üzere yüzey alanı büyümüştür. Katalizörün çözünmesi heterojen katalizör sistemlerinde oldukça sık rastlanan önemli bir problemdir. Ancak katalizörün aktifliğinin tekrar kullanımlarda başarısı; reaksiyon karışımında çözünmüş aktif merkezlerinde heterojen reaksiyon yanında homojen olarak reaksiyonu katalizlediğini göstermektedir. 
Tablo 2. Sentezlenen katalizörlerin tekrar kullanımda aktifliklerinin karşılaştırılması (Comparison of the activity in repeated use of the synthesized catalyst)

\begin{tabular}{|c|c|c|c|c|}
\hline Katalizörler & $\begin{array}{l}\text { Bazik Kuvvet } \\
(\text { pKa değeri = H_) }\end{array}$ & $\begin{array}{l}\text { Baziklik } \\
(\mathrm{mmol} / \mathrm{g})\end{array}$ & $\begin{array}{l}\mathrm{BET} \\
\left(\mathrm{m}^{2} / \mathrm{g}\right)\end{array}$ & $\begin{array}{l}\text { Trigliserit } \\
\text { Dönüşümü } \\
\mathrm{X}_{\mathrm{TG}}(\%)\end{array}$ \\
\hline$\% 5 \mathrm{~K}_{2} \mathrm{CO}_{3} / \mathrm{CaO}$ (1. kullanım) & $15<\mathrm{H}_{-}<18,4$ & 0,69 & 16,27 & 96,50 \\
\hline$\% 5 \mathrm{~K}_{2} \mathrm{CO}_{3} / \mathrm{CaO}$ (2. kullanım) & $7,2<\mathrm{H}_{-}<9,8$ & 0,26 & - & 96,00 \\
\hline$\% 5 \mathrm{~K}_{2} \mathrm{CO}_{3} / \mathrm{CaO}^{*}$ (1. kullanım) & $15<\mathrm{H}_{-}<18,4$ & 1,02 & 3,77 & 94,00 \\
\hline$\% 5 \mathrm{~K}_{2} \mathrm{CO}_{3} / \mathrm{CaO}^{*}$ (2. kullanım) & $7,2<\mathrm{H}-<9,8$ & 0,30 & 5,27 & 93,50 \\
\hline
\end{tabular}

Reaksiyon koşulları: metanol/yağ $=15 / 1$, sıcaklık $=333 \mathrm{~K}$, reaksiyon süresi: 8 saat, katalizör miktarı = ağırlıkça $\% 3$.

*Kalsinasyon sicaklığ 1 ve zamanı, $773 \mathrm{~K}$ ve 3 saat.

\section{SONUÇLAR (CONCLUSIONS)}

Kalsiyum oksitin katalitik aktivitesi içerisine belli oranlarda potasyum karbonatın kuruluğa kadar emdirme yöntemiyle eklenerek artırılmıştır. \%5 $\mathrm{K}_{2} \mathrm{CO}_{3} / \mathrm{CaO}$ kalsine edilmeyen katalizör varlığında $333 \mathrm{~K}, 15 / 1 \mathrm{metanol} /$ yağ mol oranında, \%3 katalizör miktarında 8 saat sonunda $\% 97$ metil ester verimi elde edilmiştir. Kalsine edilen ve kalsine edilmeyen $\% 5$ $\mathrm{K}_{2} \mathrm{CO}_{3} / \mathrm{CaO}$ katalizörleri iki kere aynı şartlarda reaksiyona katıldıklarında ikinci kullanım sonunda her iki katalizörün de bazik kuvvet aralığı gerilemiş ve beklendiği üzere yüzey alanı büyümüştür. Fakat her iki katalizör varlığında gerçekleştirilen reaksiyonda da trigliserit dönüşümü fazla değişmemiştir. Sentezlenen katalizörlerin aktifliğinin tekrar kullanımlarda başarısı; reaksiyon esnasında reaksiyon karışımında çözünmüş aktif merkezler sayesinde heterojen katalizli reaksiyon yanında homojen katalizli reaksiyonun da yürüdüğünü göstermektedir. Kalsine edilen katalizörde yapı daha kararlı kalsite dönüşürken, kalsine edilmeyen yapıda reaksiyon ortamında çözünebilen kalsiyum hidroksit yapısı daha baskın elde edilmiştir. Kalsine edilen \%5 $\mathrm{K}_{2} \mathrm{CO}_{3} / \mathrm{CaO}$ katalizörlerinin kanola yağından biyodizel üretimi için oldukça başarılı bir katalizör olarak kullanılabileceği düşünülmektedir.

\section{TEŞEKKÜR (ACKNOWLEDGEMENT)}

$\mathrm{Bu}$ çalışmanın gerçekleşmesi için TÜBİTAK106M041 projesi kapsamında gerekli araştırma ödeneğini sağlayan TÜBİTAK’a teşekkür ederim.

\section{KAYNAKLAR (REFERENCES)}

1. Van Gerpen, J., "Biodiesel processing and production", Fuel Processing Technology, Cilt 86, 1097-1107, 2005.

2. Kiss, A. A., Dimian, A. C., and Rothenberg, G., "Solid acid catalysts for biodiesel productiontowards sustainable energy", Advanced Synthesis \& Catalysis, Cilt 348, 75-81, 2006.

3. Canakci, M., Van Gerpen, J., "Biodiesel production from oils and fats with high free fatty acids", Transactions of the ASAE, Cilt 44, No 6, 1429-1436, 2001.
4. Canakci, M., Van Gerpen, J., "Biodiesel production via acid catalysis", Transactions of the ASAE, Cilt 42, 1203-1210, 1999.

5. Meher, L. C., Vidya Sagar, D., and Naik, S. N., "Technical aspects of biodiesel production by transesterification-A review, Renewable \&Sustainable Energy Reviews, Cilt 10, 248268, 2006.

6. Du, W., Xu, Y., Zeng, J., Liu,D., "Novozym 435catalysed transesterification of crude soy bean oils for biodiesel production in a solvent-free medium", Biotechnology and Applied Biochemistry, Cilt 40, No, 187-190, 2004.

7. Jegannathan, K.R., Abang, S., Poncelet, D., Chan, E.S., Ravindra, P., "Production of Biodiesel Using Immobilized Lipase-A Critical Review", Critical Reviews in Biotechnology, Cilt 28, No 4, 253-264, 2008.

8. Marchetti, J.M., Miguel V.U., Errazu A.F., "Possible methods for biodiesel production", Renewable and Sustainable Energy Reviews, Cilt 11, No 6, 1300-1311, 2007.

9. Keskin, A., Gürü, M. ve Altıparmak, D., "Investigation of $90 \%$ Blend of Tall Oil Biodiesel Fuel with Diesel Fuel As Alternative Diesel Fuel", Journal of the Faculty of Engineering \& Architecture of Gazi University, Cilt 22, No 1, 57-63, 2007.

10. Keskin, A., Gürü, M. ve Altıparmak, D.,'Influence Of Tall Oil Biodiesel With Mg And Mo Based Fuel Additives On Diesel Engine Performance And Emission", Bioresource Technology, Cilt 99, No 14, 6434-6438, 2008.

11. Boz, N., Sunal, O., "Kanola Yağından Çinko Oksit-destekli Katalizör Varlığında Biyodizel Üretimi”, Journal of the Faculty of Engineering \& Architecture of Gazi University, Cilt 24, No 3, 389-395, 2009.

12. Degirmenbasi, N., Ozgun, B., "Quinaldinium chlorochromate supparted on alumina: A new and efficient reagent fro the oxidation of alcohols", Monatshefte Fur Chemie, Cilt 134, No 12, 1565-1569, 2003.

13. Veljkovic', V.B., Stamenkovic', O.S., Todorovic', Z.B., Lazic', M.L., Skala, D.U., "Kinetics of Sunflower Oil Methanolysis 
Catalyzed by Calcium Oxide", Fuel, Cilt 88, 1554-1562, 2009.

14. Degirmenbasi, N., Ozgun, B., "Kinetics of oxidation of substituted benzyl alcohols by quinaldinium chlorochromate", Journal of Chemical Research-S, Cilt 1, 32-33, 1997.

15. N. Boz, M. Kara, M., "Solid base catalyzed transesterification of canola oil", Chemical Engineering Communications, Cilt 196, 80-92, 2009.

16. Boz, N., Kara, M., Sunal, O., Alptekin, E., Değirmenbaşı, N., "Investigation of Fuel Properties of Biodiesel Produced over Aluminabased Solid Catalyst", Turkish Journal of Chemistry, Cilt 33, 433-442, 2009.

17. Huaping, Z.H.U., Zongbin, W.U., Yuanxiong, C., Ping, Z., Shijie, D., Xiaohua, L.I.U., Zongqiang, M.A.O., "Preparation of biodiesel catalyzed by solid super base of calcium oxide and its refining process", Chinese Journal of Catalysis, Cilt 27, No 5, 319-396, 2006.

18. Reddy, C.R.V, Oshel, R., Verkade, J.G., "RoomTemperature Conversion of Soybean Oil and Poultry Fat to Biodiesel Catalyzed by Nanocrystalline Calcium Oxides", Energy and Fuels, Cilt 20, 1310-1314, 2006.

19. Kouzu, M., Kasuno, T., Tajika, M., Sugimoto, Y., Yamanaka, S., Hidaka, J., "Calcium oxide as a solid base catalysts for transesterification of soynean oil and its application to biodiesel production", Fuel, Cilt 87, 2798-2806, 2008.

20. Yan, S., Kim, M., Salley, S.O., Simong Ng, K.Y., "Oil transesterification over calcium oxides modified with lanthanum", Applied Catalysis A: General, Cilt 360, 163-170, 2009.

21. Ngamcharussrivichai, C., Totarat, P., Bunyakiat, $\mathrm{K}$., " $\mathrm{Ca}$ and $\mathrm{Cn}$ oxides as a heteroheneous base catalyst for transesterification of palm kernel oil", Applied Catalysis A: General, Cilt 341, 77-85, 2008.

22. Meher, L.C., Vidya Sagar, D., Naik, S.N., 'Technical aspects of biodiesel production by transesterification-a review', Renewable \& Sustainable Energy Reviews, Cilt 10, 248-268, 2006.

23. Watkins, R.S., Lee, A.F., Wilson, K., "Li-CaO catalysed tri-glyceride transesterification for biodiesel applications", Green Chemistry, Cilt 6, 335-340, 2004.

24. Meher, L.C., Kulkarni, M.G., Dalai, A.K., Naik, S.N., "Transesterification of karanja (Pongamia pinnata) oil by solid basic catalysts", European Journal and Lipid Science Technologies, Cilt 108, 389-397, 2006.

25. Benjumea, P., Agudelo, J., Agudelo, A., "Basic properties of palm oil biodiesel-diesel blends", Fuel, Cilt 87, 2069-2075, 2008.

26. Srivastava, P.K., Verma, M., "Methyl ester of karanja oil as an alternative renewable source energy", Fuel, Cilt 87, 1673-1677, 2008.

27. Soetaredjo, F.E., Ayucitra, A., Ismadji, S., Maukar, A.L., "KOH/Bentonite catalysts for transesterification of palm oil to biodiesel", Applied Clay Science, Cilt 53, No 2, 341-346, 2011.

28. American Oil Chemists' Society, Official test method Cd 3a-63 for acid value, in Official Methods and Recommended Practices of the American Oil Chemists' Society, Champaign, Ill, 1998.

29. Xie, W., Li, H., "Alumina-supported potassium iodide as a heterogeneous catalyst for biodiesel production from soybean oil", Journal of Molecular Catalysis A: Chemical, Cilt 255, 1-9, 2006.

30. European Standard of EN 14103, 'Fat and oil derivatives-Fatty Acid Methyl Esters (FAME) Determination of ester and linolenic acid methyl ester contents', April 2003.

31. AOCS. 'Official test method Ca 14-56 for total, free, and combined glycerol (iodometric-periodic acid method)', In Official Methods and Recommended Practices of the American Oil Chemists Society. Champaign, III.: AOCS, 1991.

32. Boz, N., Değirmenbaşı, N., Kalyon, D.M., "Conversion of Biomass to Fuel: Transesterification of Vegetable Oil to Biodiesel using KF Loaded Nano- $\gamma-\mathrm{Al}_{2} \mathrm{O}_{3}$ as Catalyst", Applied Catalysis B: Environmental, Cilt 89, 590-596, 2009.

33. Boz, N., Değirmenbaşı, N., Kalyon, D.M., "Transesterification of canola oil to biodiesel using calcium bentonite functionalized with $\mathrm{K}$ compounds", Applied Catalysis B: Environmental, Cilt 138-139, 236-242, 2013.

34. Degirmenbasi, N., Boz, N., Kalyon, D.M., "Biofuel Production via Transesterification using Sepiolite-supported Alkaline Catalysts, Applied Catalysis B: Environmental, Cilt 150-151, 147156, 2014. 